University of Nebraska - Lincoln

DigitalCommons@University of Nebraska - Lincoln

$1-2006$

\title{
The Impact of Support Received and Support Provision on Changes in Perceived Social Support among Older Adults
}

Kimberly A. Tyler

University of Nebraska-Lincoln, kim@ktresearch.net

Follow this and additional works at: https://digitalcommons.unl.edu/sociologyfacpub

Part of the Sociology Commons

Tyler, Kimberly A., "The Impact of Support Received and Support Provision on Changes in Perceived Social Support among Older Adults" (2006). Sociology Department, Faculty Publications. 64.

https://digitalcommons.unl.edu/sociologyfacpub/64

This Article is brought to you for free and open access by the Sociology, Department of at DigitalCommons@University of Nebraska - Lincoln. It has been accepted for inclusion in Sociology Department, Faculty Publications by an authorized administrator of DigitalCommons@University of Nebraska - Lincoln. 


\title{
THE IMPACT OF SUPPORT RECEIVED AND SUPPORT PROVISION ON CHANGES IN PERCEIVED SOCIAL SUPPORT AMONG OLDER ADULTS*
}

\author{
KIMBERLY A. TYLER, PH.D. \\ University of Nebraska-Lincoln
}

\begin{abstract}
The current study uses longitudinal data from the 1993 U.S. Midwest floods to examine the influence of support received and support provision on changes in perceived social support among older adults exposed to an acute stressor. Results indicated that flood exposure and higher levels of social support at Time 1 were positively associated with both receiving social support and providing social support specific to the food. Individuals with higher levels of support provision and received support in turn reported higher levels of perceived support post disaster. Women were more likely to have received flood specific support and to have perceived higher social support post flood. This study provides support and elaboration of earlier findings that link disaster exposure to post-disaster changes in perceived social support.
\end{abstract}

\section{INTRODUCTION}

Receipt of social support is an important factor in maintaining psychological well being following exposure to acute stressors (Bolin, 1986; Hobfall, Freedy, Lane, \& Geller, 1990; Solomon, 1986). For example, older adults with higher levels of social support have been found to experience lower levels of depressive symptoms following exposure to flooding (i.e., an acute stressor) (Tyler \& Hoyt,

\footnotetext{
*This article is based on research supported by the National Institute of Mental Health (MH48165).
} 
2000). The very nature of acute stressors, such as natural disasters, can influence the availability of support in either positive or negative directions (Freedy, Kilpatrick, \& Resnick, 1993; Kaniasty, Norris, \& Murrell, 1990; Solomon, Smith, Robins, \& Fischbach, 1987). One unique aspect of disasters and similar emergency situations is that entire support networks may be impacted. The very breadth of impact of these types of stressors means that persons who are typically sources of support for others may themselves be in need of support, and thus, the need to provide support for others may itself become a source of stress (Shumaker \& Brownell, 1984; Solomon, 1986; Solomon et al., 1987). This would seem to be particularly true among older, retired rural individuals who typically have fewer financial resources and may be experiencing greater health limitations (cf. Dorfman, 1995) while responding to disaster-related stressors (Kilijanek \& Drabek, 1979). Older women may face additional demands since the burden of supplying social support typically weighs more heavily on them compared to men (Kessler \& McLeod, 1984). Finally, social support networks typically shrink in size with age due to deaths of friends, family, and other social support members; therefore, we would expect that as individuals age into their 70s and 80s, they have smaller networks and fewer people to rely on in times of need. Not only do some older people have fewer individuals to rely on but network members may include persons from their outer circle (e.g., neighbors or professionals), rather than close intimate friends and family (Kahn \& Antonucci, 1981) suggesting that these peripheral people may not be as willing to provide the support necessary in dealing with different stressors. Additionally, older adults may feel uneasy asking neighbors or professionals for help due to concerns of burdening others, loss of independence, being rejected, becoming indebted, and/or having to reciprocate (Nadler, 1997; Nadler \& Fisher, 1986). Overall, having low levels of social support and having to provide social support to others may both be a source of strain which may be exacerbated in the context of a natural disaster. The purpose of the current study is to examine the influence of support received and support provision on changes in perceived social support among older adults exposed to an acute stressor. This study is important because disaster situations can have implications for individual's psychological well being, which may depend upon the level of social support that they believe they have available from network members.

\section{LITERATURE REVIEW}

Traditionally, research on the role of social support in coping with stress has focused on two key relationships. First, the buffering hypothesis claims that social support benefits individuals in times of crisis (Cobb, 1979) and that individuals with a strong social support network should be better able to cope with major events than those with little or no support who may be particularly vulnerable to life change (Thoits, 1982). Those experiencing a significant life event 
but who have a strong social support group should experience reduced detrimental effects compared to those with little or no social support (Lin \& Dean, 1984; Tyler \& Hoyt, 2000). Alternatively, the main effects model of social support suggests that support has positive effects directly on physical and psychological health independent of stress (Russell \& Cutrona, 1991). Empirically, the evidence provides some support for each of these conceptualizations (Cohen \& Wills, 1985; Cutrona \& Russell, 1987; Kaniasty \& Norris, 1992; Kessler \& McLeod, 1984; Norris \& Murrell, 1984).

\section{Social Support in the Context of Disaster}

In the context of natural disasters, a third perspective has emerged. Some researchers have proposed a deterioration model of social support (Barrera, 1986; Kaniasty \& Norris, 1993; Lepore, Evans, \& Schneider, 1991; Wheaton, 1985). Unlike the buffering and mobilization models, this perspective argues that exposure to stressful events deteriorates perceived social support, which in turn heightens distress. Empirical support for the model has been demonstrated in various contexts such as household crowding (cf. Lepore et al., 1991) and in the area of disaster (Kaniasty \& Norris, 1993). In the latter context, social support may be thought of as a resource that to some extent may not be renewable. The reliance on informal network support in the context of the types of stressors introduced in natural disasters may represent a unique set of demands. The capacity of the network to maintain support over the duration of need may be strained due to the fact that the impact of disasters are widespread and likely to disrupt entire social networks (Solomon, 1986).

The research indicates that victims of disasters rely heavily on their informal social networks and only contact formal service agencies as a last resort (Solomon, 1986). Further, individuals who seek formal help from mental health agencies and social service organizations have smaller networks and less effective support than individuals in the general population (Auslander \& Litwin, 1990). They are also reported to be more psychologically impaired than those seeking no help (Dew, Dunn, Bromet, \& Schuilberg, 1988). Additionally, receiving aid from formal organizations (i.e., the Red Cross) tends to be highest among those who have experienced greater damage (Beggs, Haines, \& Hurlbert, 1996a). Beggs and colleagues also note that people contact formal service agencies "when demands exceed resources or when the kinds of support that are required depart significantly from the kinds of aid that are routinely provided" (Beggs, Haines, \& Hurlbert, 1996b, p. 204). Kaniasty and Norris (2000) found that tangible help, which is often associated with formal support, is least likely to be sought. Additionally, respondents were least comfortable asking outsiders for help, especially in non-emergency situations (Kaniasty \& Norris, 2000). Given that the level of flood exposure in the current study was not as severe as some other natural disasters (cf. Kaniasty \& Norris, 1993), many respondents may have 
considered this a non-emergency situation, and therefore, would rely more heavily on informal supports.

For most persons facing stress from disaster situations, the preference is to call upon family and friends (Figley, 1983; Huerta \& Horton, 1978). In the majority of cases, such aid is voluntarily offered to families without them having to request such assistance (Drabek, Key, Erickson, \& Crowe, 1975). This reliance on informal support networks appears to be present regardless of the stressors involved (Griffith, 1985; Tausig \& Michello, 1988). To a large extent, this strategy seems to be an effective one, since research indicates that individuals with strong informal networks prior to a disaster often have higher levels of support provision and successful post-disaster recovery than those without such ties (e.g., Solomon, 1986). However, there is evidence of costs associated with the reliance on these informal support systems. This is particularly true in the context of disasters where the coping abilities of many network members are strained by psychological, health, and financial concerns (Solomon, 1986). In these contexts, support provision to other members of the informal network may itself become a source of strain (Shumaker \& Brownell, 1984; Solomon et al., 1987).

\section{Social Support and Sex Differences}

Research finds that women tend to have higher levels of social support including larger support networks, more family and friends, more multiplex relationships, more frequent contact with their networks, and receive support from multiple sources compared to men (Antonucci, 1990; Antonucci \& Akiyama, 1987; Field \& Minkler, 1988; Matt \& Dean, 1993; Turner \& Marino, 1994; Vaux, 1985). However, research has also found that for women, receiving support was associated with feelings of guilt and providing support was related to feelings of burden (Lu, 1997). Additionally, given that men are more likely to receive support from their wives whereas women are more likely to receive support from children, friends, and relatives (Gurung, Taylor, \& Seeman, 2003), women are likely to have larger networks, which may translate into more support but also more burden for women. Moreover, because men are less likely to seek or accept support, regardless of need (Beggs et al., 1996b), we would expect men to provide less support due to the norm of reciprocity. Overall, much of the research finds gender differences in terms of social support.

In the disaster literature, research has also found that women have more support available (Drabek et al., 1975; Solomon et al., 1987) and receive more support from others compared to men (Norris \& Kaniasty, 1996). Since women tend to have higher levels of perceived support and received support, one would expect them to report higher levels of well being compared to men. However, women are also likely to have numerous network members who potentially may rely on them for support (Solomon, 1986), which may increase the risk for conflict (Antonucci, 1990), and if women have less control over the demands placed upon 
them, social support may not have the same positive impact for them as it does for men (Solomon, 1986).

\section{Current Study}

This study addresses the abovementioned issues with longitudinal data from the 1993 U.S. Midwest floods. The occurrence of the disaster one year after a statewide mental health survey was conducted allowed for a prospective look at the impact of the event on social support. A sample of Iowa residents, all of who lived in an area impacted by the flood, participated in interviews one year prior to and 30 to 90 days after the disaster. Based on the deterioration model of social support and the above findings, I sought to examine: a) if support received and support provision impacted perceptions of available support post-disaster, and b) if any such relationships differed by gender. Specifically, it was hypothesized that prior levels of perceived support would be positively associated with support received and support provision. Second, it was expected that support received and support provision would each be positively related to Time 2 perceived support controlling for Time 1 social support. Finally, it was hypothesized that women would have higher levels of support received, support provision, and perceived social support compared to men.

\section{METHOD}

\section{Sample}

The sample is from the Iowa Health Poll, which is a statewide survey designed to provide information on mental health and health needs and services in rural and urban Iowa. Interviews for the first survey, which was completed in the spring of 1992, took an average of 22 minutes to complete. Questions on numerous topics, such as health, mental health, stressful life events, social support, and household demographics, were included. Respondents were randomly selected from eligible adults in a screened household where the response rate was $76 \%$.

Coincidentally, during the summer of 1993, urban and rural residents in the state of Iowa experienced a series of severe storms. Due to one of the worst floods in Iowa's history, the entire state was declared a disaster area in July of 1993. The storms, which lasted for months, brought constant record-breaking rains to nine states throughout the summer (McPhee, 1996). Although there was minimal loss of life due to the Midwest flooding, there was extensive and widespread damage, as well as financial loss.

In the fall of 1993, approximately 60 days after the peak impact of the flooding in the Midwest, respondents of the first survey were contacted and requested to participate in a second interview. Of the original sample, $82 \%$ were successfully re-interviewed. This survey repeated the original questions on health and mental 
health, as well as addressing the potential impacts of the 1993 floods. Expanded measures of perceived social support were also included in the second interview given the potential impact of flood exposure on perceptions of emotional support. The analyses for the current study were based on 517 respondents who completed both interviews. Their ages ranged from 55 to 90 with a mean of 67 years. Sixty percent were married and $66 \%$ were female. Although the flood impacted the entire area, $46 \%$ of older respondents indicated that they had experienced direct exposure and $12 \%$ reported exposure that was indirect. Overall, $47 \%$ of older individuals reported experiencing flood exposure that was either direct and/or indirect. It is important to recognize that the flooding was a community event that could have consequences even for those who did not experience any direct losses (cf. Kaniasty \& Norris, 1993).

\section{Measures}

\section{Perceived Emotional Social Support-Time 1}

Perceived emotional social support at Time 1 consisted of two items from Ross and Huber, (1985), which measured perceived availability of emotional support. Response categories ranged from (1) strongly agree to (4) strongly disagree, and the two questions included: "I have someone I can really talk to" and "I have someone I can turn to for support and understanding when things get rough." Items were reverse coded and summed such that the higher the score, the higher the level of perceived emotional social support. The bivariate correlation between these two items is .55 .

\section{Perceived Emotional Social Support-Time 2}

Perceived emotional social support at Time 2 was assessed using the Social Provisions Scale (Cutrona \& Russell, 1987), which measured perceived availability of emotional support. Because of the coincidence of the flood, measures of social support were expanded at Time 2. A reduced version of the Social Provision Scale (Cutrona \& Russell, 1987), which was derived from analyses of other data sets (Russell, personal correspondence), was used in the current study. Respondents were asked to rate the degree to which their social relationships are currently supplying social integration, attachment, reassurance, alliance, and guidance. For example, "There are people I can depend on to help me if I really need it," and "I have close relationships that provide me with a sense of emotional security and well-being." Responses ranged from (1) strongly agree to (4) strongly disagree (see Appendix for a list of all support items). For scoring purposes, the negative items were reverse coded and summed together with the positive items to form a score for each social provision. The five provisions were weighted and then added to form an overall measure of social support. Cronbach's alpha for this measure is .88 . 


\section{Support Received}

Support received was a four-item indicator, which measured receipt of floodspecific emotional support covering four domains. The provisions include relying on others for advice, trust, comfort, and alliance (see Appendix for exact wording of questions). These items have been used in prior research on natural disasters (Solomon et al., 1987).

\section{Support Provision}

Support provision was measured using four items which focused on floodspecific emotional support provided to others covering the same domains as support received (Solomon et al., 1987). (See Appendix for exact wording of questions.)

\section{Flood Exposure}

Flood exposure was measured by asking respondents a series of questions at Time 2 (see Table 1). These questions were adapted from Smith and associates (1989) and focused on how individuals and their families were affected by the weather and flooding in the Midwest (Smith, Robins, Przybeck, Goldring, \& Solomon, 1989). The flood exposure measure, which consisted of 19 items, was computed by performing a count procedure of all items that included both direct and indirect exposure. Direct exposure items included such stressors as having an illness or injury as a result of the flood or having to temporarily evacuate or move out of one's home due to flooding. Indirect exposure items assessed whether other family members had experienced loss, damage, or injury due to flooding. Due to skewness, this variable was then dichotomized into 0 (no flood exposure) and 1 (flood exposure).

\section{Control Variables}

Control variables included living status (rural/urban), personal stress, economic stress, health limits, marital status, income, age, and gender. Living status measured whether respondents lived on a farm/country, in a rural town (less than 2,500), a town $(2,500$ to 9,999$)$, a city $(10,000-49,999)$ or in a SMSA (50,000 or greater). Personal stress was a count of four stressful life events in the past year (e.g., had someone in your household get very ill or injured and had a close relative or friend die). Economic stress was assessed by asking respondents about their economic situation in the past year (e.g., have you had a substantial decline in your income and have you had problems paying your bills on time). This measure was also a count of four items such that the higher the score, the higher the economic stress. Health limits consisted of six items, which focused on the types and extent of health limitations. For example, "Are you limited in moving around in your home without assistance a lot, somewhat 
Table 1. Flood Exposure Questions

Item

Percent Yes

response

1. Have you had to temporarily evacuate or move out of your home any time since June 1993 because of problems with water or flooding?

2. Did you get water in your home from the flooding this summer? $\quad 10.4$

3. Was there water on your property?

20.9

4. Were you temporarily or permanently out of work due to the flood?

5. Were other members of your household temporarily or permanently out of work due to the flood?

6. Did you or other household members lose income due to the flood?

7. Did you lose water service due to the flood?

8. Did you lose electrical service due to the flood?

9. Did you have any illness or injury as a result of the flood?

10. Was anyone else in your household ill or injured as a result of the flood?

11. Did you experience any damage or loss to your property or possessions?

12. I am going to read a list of items, please identify any losses or damage that you had because of the flood.

Did you experience any damage or loss to your . . .
a. House
6.2
b. Furniture or appliances
5.0
c. Family heirlooms/mementos
d. Clothes
e. Car/truck
0.6
f. Crops
9.4
g. Land (topsoil)
8.7
h. Access road to your home
1.8 
or not at all?" and "Are you limited in climbing a flight of stairs a lot, somewhat, or not at all?" A higher score indicates more health limitations. Marital status was dummy coded such that those who were currently married or living with a partner were coded as 1 , whereas those who were not currently married were coded as 0 . Not currently married included those who were divorced, separated, widowed, or never married. Income was an ordinal measure of 10 income categories in increments of $\$ 5,000$, and gender was coded $0=$ males and $1=$ females.

\section{Procedure}

Ordinary least squares (OLS) regression was used to determine how perceived emotional social support at Time 1 and flood exposure influenced receipt of support and provision of support and how all four of these variables in turn affected perceived emotional support at Time 2. A total of three models were estimated (see Table 2). The current study also tested for gender interactions in each of the three models. Due to the possibility that some of the variables (e.g., support received and support provision) could be highly correlated variance inflation factors (VIFs) were checked. This is a formal method that is used to detect the presence of multicollinearity. "These factors measure how much the variances of the estimated regression coefficients are inflated as compared to when the predictor variables are not linearly related" (Neter, Kutner, Nachtsheim, \& Wasserman, 1996, p. 386). Collinearity did not appear to be a problem in any of the models because variance inflation factors were all well below 10 (Neter et al., 1996).

\section{RESULTS}

Regression models for perceptions of emotional social support are presented in Table 2. Model 1 (see Table 2) indicated that perceived emotional social support at Time $1(\beta=.10)$ and flood exposure $(\beta=.38)$ were positively related to support received. Control variables significantly related to support received, specific to the flood, included marital status $(\beta=-.11)$, income $(\beta=.12)$, and gender $(\beta=.11)$. Model 1 explained $18 \%$ of the variance in support received.

Model 2 (see Table 2) revealed that support provision, specific to the flood, was positively related to flood exposure $(\beta=.24)$ and pre flood levels of emotional social support $(\beta=.08)$. The two significant control variables in Model 2 included living status (rural/urban) $(\beta=.10)$ and age $(\beta=-.13)$ indicating that younger aged respondents and those who lived in higher populated areas were more likely to have provided support to others. Model 2 explained $8 \%$ of the variance in support provision.

Results from Model 3 (see Table 2) revealed that both support provision $(\beta=.11)$ and support received $(\beta=.13)$ were significantly related to increases 
Table 2. Regression Models for Perceptions of Emotional Social Support among Older Adults

\begin{tabular}{|c|c|c|c|c|c|c|}
\hline \multirow[b]{2}{*}{ Independent variables } & \multicolumn{2}{|c|}{$\begin{array}{l}\text { Support } \\
\text { received } \\
\text { Model } 1\end{array}$} & \multicolumn{2}{|c|}{$\begin{array}{l}\text { Support } \\
\text { provision } \\
\text { Model } 2\end{array}$} & \multicolumn{2}{|c|}{$\begin{array}{l}\text { Perceived support } \\
\text { Time } 2 \\
\text { Model } 3\end{array}$} \\
\hline & $\mathrm{B}$ & $\beta$ & $\mathrm{B}$ & $\beta$ & $\mathrm{B}$ & $\beta$ \\
\hline Social support Time 1 & .16 & $.10 * \star$ & .08 & $.08^{*}$ & .55 & $.24^{* *}$ \\
\hline Flood exposure $(0=n o)$ & 1.40 & $.38^{* *}$ & .53 & $.24^{\star *}$ & -.48 & $-.10^{\star}$ \\
\hline Rural/urban & .02 & .02 & .07 & $.10^{*}$ & .06 & .04 \\
\hline Personal stress & -.07 & -.03 & .06 & .04 & -.11 & -.03 \\
\hline Economic stress & -.01 & .00 & .08 & .06 & -.09 & -.03 \\
\hline Health limits & .08 & .04 & .05 & .04 & .17 & .06 \\
\hline Marital status $(0=$ unmarried $)$ & -.40 & $-.11^{*}$ & -.17 & -.08 & -.19 & -.04 \\
\hline Income & .10 & $.12^{\star}$ & .02 & .04 & .20 & $.17^{\star \star}$ \\
\hline Age & -.01 & -.06 & -.02 & $-.13^{* *}$ & -.04 & $-.13^{\star \star}$ \\
\hline Gender $(0=$ male $)$ & .43 & $.11 * *$ & .01 & .01 & .56 & $.10^{*}$ \\
\hline Support provision & - & - & - & - & .26 & $.11^{\star}$ \\
\hline Support received & - & - & - & - & .18 & $.13^{* *}$ \\
\hline Constant & .84 & & .74 & & 18.95 & \\
\hline Adjusted $R^{2}$ & .18 & & .08 & & .16 & \\
\hline
\end{tabular}

in perceived emotional support at Time 2. Perceived social support at Time 1 $(\beta=.24)$ and flood exposure $(\beta=-.10)$ were both related to Time 2 social support. In terms of control variables, income $(\beta=.17)$, age $(\beta=-.13)$, and gender $(\beta=.10)$ were significantly associated with perceived support at Time 2 . This model explained $16 \%$ of the variance in perceived emotional social support at Time 2 . 
Since the literature finds that men and women tend to differ in the size and composition of their networks (Antonucci \& Akiyama, 1987) and that the burden of providing support typically weighs more heavily on women (Kessler $\&$ McLeod, 1984), the current study tested for gender interactions in each of the three models. Results (not shown) revealed no significant gender interactions, which means that the effects of the independent variables on the dependent variables (e.g., flood exposure on support receipt) did not differ significantly for men and women.

\section{DISCUSSION}

Three noteworthy findings emerged from this study. First, flood exposure was positively associated with flood specific receipt of support and flood specific support provision but was negatively associated with perceived support at Time 2 . Second, receipt of social support and support provision were positively related to perceptions of support post disaster. Finally, compared to men, women received higher levels of flood specific support and reported higher levels of perceived support at Time 2 .

As hypothesized, social support at Time 1 was positively related to each of the three outcome variables indicating that those who reported higher levels of social support at Time 1 were more likely to have received support, provided support to others, and to report higher levels of support available even after the flood.

Flood exposure had a positive influence on receipt of support and support provision indicating that older individuals who experienced flood exposure were more likely to report receiving, as well as providing, support to others. This is one unique aspect of disasters; individuals receive social support, but because others in their network are likely to be impacted, they are responsible for providing them with support as well. It is possible that providing this support to others may itself be a source of additional stress (Shumaker \& Brownell, 1984; Solomon, 1986), especially when already dealing with an acute stressor. The positive association between exposure and receipt of support is consistent with the findings of Norris and Kaniasty (1996) and the support mobilization model (Barrera, 1986) such that exposure to an acute stressor triggers support from the social network (receipt of support).

The findings also revealed that having experienced flood exposure resulted in a decrease in perceptions of social support post flood. This finding is consistent with the deterioration model such that exposure to stressful events deteriorates perceived social support. This in turn, is expected to heighten distress. Our previous findings with this sample revealed that older adults with lower levels of social support experienced higher levels of depressive symptoms following exposure to flooding (Tyler \& Hoyt, 2000). Consistent with the literature, the current findings reveal that the very nature of acute stressors, such as natural disasters, can influence the availability of support in either positive or negative 
directions (Freedy et al., 1993; Kaniasty et al., 1990; Solomon et al., 1987). In the context of disaster, social support may be thought of as a resource that to some extent may not be renewable. The reliance on informal network support in the context of the types of stressors introduced in natural disasters may represent a unique set of demands. The capacity of the network to maintain support over the duration of need may be strained due to the fact that the impact of disasters are widespread and are likely to disrupt entire social networks (Solomon, 1986).

The positive association between receipt of support, support provision and Time 2 social support can be explained by the norm of reciprocity. That is, utilizing support from social networks means that the older individual is expected to repay the people who provided the support (cf. Lu, 1997; Shinn, Lehmann, $\&$ Wong, 1984). Therefore, being exposed to the flood triggered support from others, but it also suggests that others requested their help. Receiving support and providing support may lead older individuals to believe that future support will be available. However, these findings differed by gender. In Model 1, women received higher levels of social support specific to the flood compared to men, which is consistent with the research in this area (Drabek et al., 1975; Solomon et al., 1987). One possible explanation for this finding is that women may actively request more help than men, which is consistent with the work of Beggs et al. (1996b). Additionally, because men have less contact with friends as they age (cf. Field \& Minkler, 1988) they may feel uncomfortable calling on such people for social support. However, because the contacts of older women have been found to remain unchanged over time (Field \& Minkler, 1988), women may be more apt to ask for assistance. Another possibility may be that women do have larger social support networks, more frequent contact with their networks, and multiple sources compared to men; therefore, they receive more social support. The positive association found between support received and being female is consistent with the literature (cf. Antonucci, 1990; Antonucci \& Akiyama, 1987; Lu, 1997; Turner \& Marino, 1994; Vaux, 1985).

Although some literature finds that women have larger support networks (Antonucci \& Akiyama, 1987) and experience more support burden compared to their male counterparts (Kessler \& McLeod, 1984), no support was found for the burden hypothesis in the current study. That is, gender was not significantly associated with support provision. One possible explanation may be due to the nature of the acute stressor. That is, because the stressor focused on indicators of flood exposure, such as having your property flooded or having water in your home, both men and women may have been likely to be called upon. Under these circumstances, in addition to some people needing emotional support, many may have also requested instrumental support, and men may have been just as likely as women to have been called on. Another reason for the lack of a sex difference for support provision may be due to the widespread nature of the flood, which resulted in many people needing help; therefore, both men and women were likely to be called upon to provide support. 
Women perceived higher levels of social support at Time 2 compared to men. It is possible that because women were more likely than men to have previously received support specific to the flood, women may have believed that future support would be available. In contrast, it is possible that men did not receive adequate support related to the flood; therefore, they may believe that less social support will be available in the future.

In terms of study limitations, it should be noted that the flooding that the older individuals in the current study experienced was not as severe as some other natural disasters (cf. Kaniasty \& Norris, 1993). As such the findings may not be directly comparable to other disasters where there have been more severe losses and trauma exposure. In part, this limitation is addressed by treating the flooding experienced by this sample as an acute stressor. Another limitation is the potential impact of attrition. It is possible with the measurement taking place soon after the flooding that some of the most impacted respondents were not contacted in the post flood interview. Another limitation is the use of brief self-report measures required for a telephone survey. This methodology placed restrictions on the types of scales used, which did not produce optimal measures in some instances (e.g., economic stress). It is important to keep in mind that with the exception of support provision, all measures of social support were based on perceptions, which may be very different from the "actual" support that may be available. Additionally, the fact that support provision measured actual support may also account for the lower explained variance in Model 2 compared to the other models. Finally, different measures of social support were used at Time 1 and Time 2. It is possible that if identical measures of social support were used at both times, the stability coefficient may have been higher but less variance may have been attributed to the other variables in the model.

Despite these limitations, the current study's focus on both provision and receipt of social support and their influence on perceived availability of future support suggest the importance of social networks in times of crisis. Although previous research has highlighted the important role that social support plays in the stress process, fewer studies have focused on changes in support over time for those exposed to an acute stressor. Additionally, even though the current study found that women were more likely to have received support, women were not significantly more likely than men to provide flood specific support to others (i.e., support provision). Although this may be in part due to the nature of the acute stressor, future studies on natural disasters and/or acute stressors may look into these support processes, comparing women and men. In addition to sex differences, it is also possible that the support process varies across age groups. Although the current study found a negative association between age and support provision and support at Time 2, no significant age interactions were found in the current study (results not shown). However, future studies may wish to replicate these findings testing for differences within older age groups exposed to similar stressors. 
In summary, these findings suggest that exposure to an acute stressor triggers support from one's social network but also results in older individuals being called upon to provide support to others, which may be a source of strain in itself. Women received more flood specific support but did not experience significantly more support provision than men. Receipt of support and support provision resulted in higher perceptions of post-disaster support.

\section{APPENDIX}

\section{Measures for Support Received and Support Provision:}

Note: The odd numbered questions measure support received and the even numbered questions measure support provision. Response categories were yes/no.

1. Since the start of the flooding, if you had an important decision to make, has there always been someone whose advice you would be likely to ask and rely on?

2. Has there been anyone who has relied on you for this type of advice since the start of the flooding?

3. Since the start of the flooding, if you made a serious mistake that could get you into trouble, has there always been someone you trusted enough to tell about it?

4. Has there been anyone who has trusted you that much since the start of the flooding?

5. Since the start of the flooding, if someone treated you badly and you were upset about it, has there always been someone you could go to for comfort?

6. Has anyone come to you for comfort because someone treated them badly and upset them since the start of the flooding?

7. Since the start of the flooding, if you had a disagreement or fight with someone, has there always been someone you could go to for comfort?

8. Has anyone counted on you to be on his or her side when he or she had a disagreement or fight with someone since the start of the flooding?

\section{Measures for Perceived Emotional Social Support:}

(Response categories for all support items included: strongly agree, agree, disagree, strongly disagree).

Time 1

1. I have someone I can really talk to. Do you ...

2. I have someone I can turn to for support and understanding when things get rough. Do you ... 


\section{Time 2}

1. There are people I can depend on to help me if I really need it. Do you . . .

2. There are people who enjoy the same social activities I do. Do you ...

3. I do not think other people respect my skills and abilities. Do you ...

4. I have close relationships that provide me with a sense of emotional security and wellbeing. Do you ...

5. There is someone I can talk to about important decisions in my life. Do you ...

6. I have relationships where my competence and skill are recognized. Do you ...

7. There is no one who shares my interests and concerns. Do you ...

8. There is no one I can depend on for aid if I really need it. Do you . . .

9. There is no one I feel comfortable talking about problems with. Do you ...

10. There are people I can count on in an emergency. Do you ...

\section{REFERENCES}

Antonucci, T. C. (1990). Social supports and social relationships. In R. H. Binstock \& L. K. George (Eds.), Handbook of aging and the social sciences (3rd ed., pp. 205-226). San Diego: Academic Press.

Antonucci, T. C., \& Akiyama, H. (1987). An examination of sex differences in social support among older men and women. Sex Roles 17, 737-749.

Auslander, G. K., \& Litwin, H. (1990). Social support networks and formal help seeking: Differences between applications to social services and a nonapplicant sample. Journal of Gerontology, 45, 112-119.

Barrera, M. (1986). Distinctions between social support concepts, measures, and models. American Journal of Community Psychology, 14, 413-445.

Beggs, J. J., Haines, V. A., \& Hurlbert, J. S. (1996a). The effects of personal network and local community contexts on the receipt of formal aid during disaster recovery. International Journal of Mass Emergencies and Disasters, 14(1), 57-78.

Beggs, J. J., Haines, V. A., \& Hurlbert, J. S. (1996b). Situational contingencies surrounding the receipt of informal support. Social Forces, 75(1), 202-222.

Bolin, R. C. (1986). Disaster characteristics and psychosocial impacts. In B. J. Sowder \& M. Lystad (Eds.), Disasters and mental health: Contemporary perspectives and innovations in services to disaster victims (pp. 11-35). Washington, DC: American Psychiatric Press.

Cobb, S. (1979). Social support and health through the life course. In M. White Riley (Ed.), Aging from birth to death: Interdisciplinary perspectives (pp. 93-106). Boulder, CO: Westview Press.

Cohen, S., \& Wills, T. A. (1985). Stress, social support, and the buffering hypothesis. Psychological Bulletin, 98, 310-357.

Cutrona, C. E., \& Russell, D. W. (1987). The provisions of social relationships and adaptation to stress. Advances in Personal Relationships, 1, 37-67.

Dew, M. A., Dunn, L. O., Bromet, E. J., \& Schulberg, H. C. (1988). Factors affecting help-seeking during depression in a community sample. Journal of Affective Disorders, 14, 223-234. 
Dorfman, L. T. (1995). Health, financial status, and social participation of retired rural men and women: Implications for educational intervention. Educational Gerontology, 21(7), 653-669.

Drabek, T. E., Key, W. H., Erickson, P. E., \& Crowe, J. L. (1975). The impact of disaster on kin relationships. Journal of Marriage and the Family, 37, 481-494.

Field, D., \& Minkler, M. (1988). Continuity and change in social support between youngold and old-old or very-old age. Journal of Gerontology, 43, P100-106.

Figley, C. R. (1983). Catastrophes: An overview of family reactions. In C. R. Figley \& H. I. McCubbin (Eds.), Stress and the family: Coping with catastrophe (Vol. 2, pp. 3-20). New York: Brunner/Mazel.

Freedy, J. R., Kilpatrick, D. G., \& Resnick, H. S. (1993). Natural disasters and mental health: Theory, assessment, and intervention. Journal of Social Behavior and Personality, 8, 49-103.

Griffith, J. (1985). Social support providers: Who are they? Where are they met?-And the relationship of network characteristics to psychological distress. Basic and Applied Social Psychology, 6, 41-60.

Gurung, R. A. R., Taylor, S. E., \& Seeman, T. E. (2003). Accounting for changes in social support among married older adults: Insights from the MacArthur studies of successful aging. Psychology and Aging, 18(3), 487-497.

Hobfoll, S. E., Freedy, J., Lane, C., \& Geller, P. (1990). Conservation of social resources: Social support resource theory. Journal of Social and Personal Relationships, 7, 465-478.

Huerta, F., \& Horton, R. (1978). Coping behavior of elderly flood victims. The Gerontologist, 18, 541-546.

Kahn, R. L., \& Antonucci, T. C. (1981). Convoys of social support: A life-course approach. In S. Kiesler, J. Morgan, \& V. Oppenheimer (Eds.), Aging: Social change (pp. 383-405). New York: Academic Press, Inc.

Kaniasty, K., \& Norris, F. H. (1992). Social support and victims of crime: Matching event, support, and outcome. American Journal of Community Psychology, 20, 211-241.

Kaniasty, K., \& Norris, F. H. (1993). A test of the social support deterioration model in the context of natural disaster. Journal of Personality and Social Psychology, 64, 395-408.

Kaniasty, K., \& Norris, F. H. (2000). Help-seeking comfort and receiving social support: The role of ethnicity and context of need. American Journal of Community Psychology, 28(4), 545-581.

Kaniasty, K., Norris, F. H., \& Murrell, S. A. (1990). Received and perceived social support following natural disaster. Journal of Applied Social Psychology, 20, 85-114.

Kessler, R. C., \& McLeod, J. D. (1984). Sex differences in vulnerability to undesirable life events. American Sociological Review, 49, 620-631.

Kilijanek, T. S., \& Drabek, T. E. (1979). Assessing long-term impacts of a natural disaster: A focus on the elderly. The Gerontologist, 19, 555-566.

Lepore, S. J., Evans, G. W., \& Schneider, M. L. (1991). Dynamic role of social support in the link between chronic stress and psychological distress. Journal of Personality and Social Psychology, 61, 899-909.

Lin, N., \& Dean, A. (1984). Social support and depression: A panel study. Social Psychiatry, 19, 83-91.

Lu, L. (1997). Social support, reciprocity, and well-being. Journal of Social Psychology, 137(5), 618-628. 
Matt, G. E., \& Dean, A. (1993). Social support from friends and psychological distress among elderly persons: Moderator effects of age. Journal of Health and Social Behavior, 34, 187-200.

McPhee, L. (Director). (1996). Flood! (NOVA Executive Producer P.S. Apsell). Boston: WGBH.

Nadler, A. (1997). Personality and help seeking: Autonomous versus dependent seeking of help. In G. Pierce, B. Lakey, I. Sarason, \& B. Sarason (Eds.), Sourcebook of social support and personality (pp. 379-407). New York: Plenum Press.

Nadler, A., \& Fisher, J. (1986). The role of threat and self-esteem and perceived control in recipient reactions to aid: Theory development and empirical validation. In L. Berkowitz (Ed.), Advances in experimental social psychology (Vol. 19, pp. 81-123). New York: Academic Press.

Neter, J., Kutner, M. H., Nachtsheim, C. J., \& Wasserman, W. (1996). Applied linear regression models (3rd ed.). Chicago: Times Mirror Higher Education Group, Inc.

Norris, F. H., \& Kaniasty, K. (1996). Received and perceived social support in times of stress: A test of the social support deterioration deterrence model. Journal of Personality and Social Psychology, 71, 498-511.

Norris, F. H., \& Murrell, S. A. (1984). Protective function of resources related to life events, global stress, and depression in older adults. Journal of Health and Social Behavior, 25, 424-437.

Ross, C. E., \& Huber, J. (1985). Hardship and depression. Journal of Health and Social Behavior, 26, 312-327.

Russell, D. W., \& Cutrona, C. E. (1991). Social support, stress, and depressive symptoms among the elderly: Test of a process model. Psychology and Aging, 6, 190-201.

Shinn, M., Lehmann, S., \& Wong, N. W. (1984). Social interaction and social support. Journal of Social Issues, 40, 55-76.

Shumaker, S. A., \& Brownell, A. (1984). Toward a theory of social support: Closing conceptual gaps. Journal of Social Issues, 40, 11-36.

Smith, E., Robins, L., Przybeck, T., Goldring, E., \& Solomon, S. (1989). Psychological consequences of a disaster. In J. Shore (Ed.), Disaster stress studies: New methods and findings (pp. 49-76). Washington, DC: American Psychiatric Press.

Solomon, S. D. (1986). Mobilizing social support networks in times of disaster. In C. R. Figley (Ed.), Trauma and its wake (Vol. 2, pp. 232-263). New York: Brunner/ Mazel.

Solomon, S. D., Smith, E. M., Robins, L. N., \& Fischbach, R. L. (1987). Social involvement as a mediator of disaster-induced stress. Journal of Applied Social Psychology, 17, 1092-1112.

Tausig, M., \& Michello, J. (1988). Seeking social support. Basic and Applied Social Psychology, 9, 1-12.

Thoits, P. A. (1982). Conceptual, methodological, and theoretical problems in studying social support as a buffer against life stress. Journal of Health and Social Behavior, 23, 145-159.

Turner, R. J., \& Marino, F. (1994). Social support and social structure: A descriptive epidemiology. Journal of Health and Social Behavior, 35, 193-212.

Tyler, K. A., \& Hoyt, D. (2000). The effects of an acute stressor on depressive symptoms among older adults: The moderating effects of social support and age. Research on Aging, 22, 143-164. 
Vaux, A. (1985). Variations in social support associated with gender, ethnicity, and age. Journal of Social Issues, 41, 89-110.

Wheaton, B. (1985). Models for the stress-buffering functions of coping resources. Journal of Health and Social Behavior, 26, 352-364.

Direct reprint requests to:

Dr. Kimberly A. Tyler, Ph.D.

University of Nebraska-Lincoln

Department of Sociology

717 Oldfather Hall

Lincoln, NE 68588-0324

e-mail: ktyler2@unl.edu 